\title{
Molecular characterisation of five metalloproteases (Mep1-5) and one subtilisin (Sub6) among Microsporum audouinii strains circulating in Belgium
}

Aouini Imen'2,3, Sacheli Rosalie',2, Rajae Darfouf ${ }^{1,2}$, Caroline Adjetey², S. Bontems²,

P. Melin², Aly Raies ${ }^{3}$, Marie Pierre Hayette ${ }^{1,2}$

${ }^{1}$ National Reference Center for Mycosis, ${ }^{2}$ Department of Clinical Microbiology, Center for Interdisciplinary Research on Medecines, University Hospital of Liège Belgium ${ }^{3}$ Laboratory of Microorganisms and active biomolecules, University of Tunis El Manar II, Tunisia

Objectives. Dermatophytes are producing proteases to digest tissue keratin and these enzymes have already been described as potential virulence factors in different zoonotic species such as Trichophyton mentagrophytes and Microsporum canis. In the present study, primers targeting five metalloproteases Mep1-5 and one subtilisin (Sub6) have been designed to screen a large scale of Microsporum audouinii strains isolated in Belgium in order to check the presence of these metalloproteases genes.

Materials and methods. Strains: 103 clinical strains collected in the National Reference Center, Liège (Belgium)/2 reference IHEM strains (BCCM, Brussels). Culture on Sabouraud dextrose agar: Identification by macroscopic and microscopic characteristics (+ITS sequencing if necessary) Culture on Sabouraud Dextrose Broth $\rightarrow$ DNA extraction by Maxwell 16 cell DNA purification kit preceded by enzymatic lysis using proteinase $\mathrm{K}$ for 20 minutes (Figure 1). Primers were newly designed based on nucleotide sequences of the genes Mep1-5 available in GenBank database for the close related species $M$. canis and using primer Blast (NCBI-NIH). Sub6 primers were derived from an unpublished study about M. canis (Anne Mathy. B.Mignon et al, 2013, University of Liège). (Table 1).

Results. Among the 103 M. audouinii strains, the presence of at least one gene encoding for Mep1-5 was revealed in 93\%

(96/103) with $80 \%$ (87/103) being positive for the five Meps (1-5) (Figures 2-3). The detection was as followed: $89 \%$ (92/103) for Mep1, 90\% (91/103) for Mep2 and Mep 5, 85\% (88/103) for Mep3 \& 92\% (95/103) for Mep4. In total, 7\% (7/103) of the strains did not express any Mep gene. An internal control of amplification (ITS sequence) was also included to exclude a false negative result due to amplification inhibitors.

\section{Results (2)}

One Portuguese study (A. Lemsaddek, Microbiol, 2010) aiming the screening of metalloproteases genes in $M$. audouinii revealed also that Mep4 was the most expressed one (100\%). Mep1 and Mep5 were detected in 96\%, Mep3 in 91\% and Mep2 in $87 \%$ of the $M$. audouinii isolates. Concerning the screening of the Sub6 gene, the analysis revealed that among the $103 \mathrm{M}$. audouinii strains, $\mathbf{8 7 \%}(\mathbf{9 0 / 1 0 3 )}$ of the isolates were positive for the Sub6 gene. An internal control of amplification (ITS sequence) was also included to exclude a false negative result in the negative samples due to amplification inhibitors.

\section{Conclusion}

The presence of the Mep1-5 genes in M. audouinii strains circulating in Belgium was confirmed in this study with $80 \%$ of the strains being positive for the five Meps. Sub6 was also present in the main strains (87\%). Fairly close percentages of expression of these genes let us think that all tested Meps and Sub6 could be implicated in the virulence process of $M$. audouinii strains. The next step will be to confirm the in vivo expression of these metalloproteases in $M$. audouinii.

\begin{tabular}{|c|c|c|c|}
\hline & \multicolumn{2}{|c|}{ Primers } & \multirow{2}{*}{$\begin{array}{l}\text { Size } \\
\text { (bp) }\end{array}$} \\
\hline Target & Forward (5'-3') & Reverse (5'-3') & \\
\hline Mep1 & $\begin{array}{c}\text { AACTCTGCTACATG } \\
\text { GCTAAG }\end{array}$ & $\begin{array}{c}\text { CATAGTCATTACCGCC } \\
\text { ATCT }\end{array}$ & 398 \\
\hline Mep2 & $\begin{array}{c}\text { CAGATGGTTCAATC } \\
\text { CTTTGC }\end{array}$ & $\begin{array}{c}\text { ATCCTTCTGGATGTAG } \\
\text { ACGA }\end{array}$ & 514 \\
\hline Mep3 & $\begin{array}{c}\text { АССТСТАСТССАСТ } \\
\text { ААССТC }\end{array}$ & $\begin{array}{c}\text { GTTGCATGGTTGACTA } \\
\text { GAGA }\end{array}$ & 304 \\
\hline Mep4 & $\begin{array}{c}\text { CCTCTATTTTCCGT } \\
\text { GGTTCA }\end{array}$ & $\begin{array}{l}\text { AACATACATGAGAGG } \\
\text { GTTCG }\end{array}$ & 801 \\
\hline Mep5 & $\begin{array}{c}\text { CCTACGTTGATGCT } \\
\text { AAAAGC }\end{array}$ & $\begin{array}{c}\text { TTACGGCCATGAGTGT } \\
\text { ATTC }\end{array}$ & 730 \\
\hline Sub6 & $\begin{array}{c}\text { GGCCATTTTCTGAT } \\
\text { GCTGGTATC }\end{array}$ & TTATTTGCCGTTGTA & 500 \\
\hline $\begin{array}{r}\text { ITS86/ } \\
\text { ITS4 }\end{array}$ & $\begin{array}{c}\text { GTGAATCATCGAAT } \\
\text { CTTTGAA }\end{array}$ & $\begin{array}{c}\text { TCCTCCGCTTATTGAT } \\
\text { ATGC }\end{array}$ & $\begin{array}{l}250- \\
300\end{array}$ \\
\hline
\end{tabular}

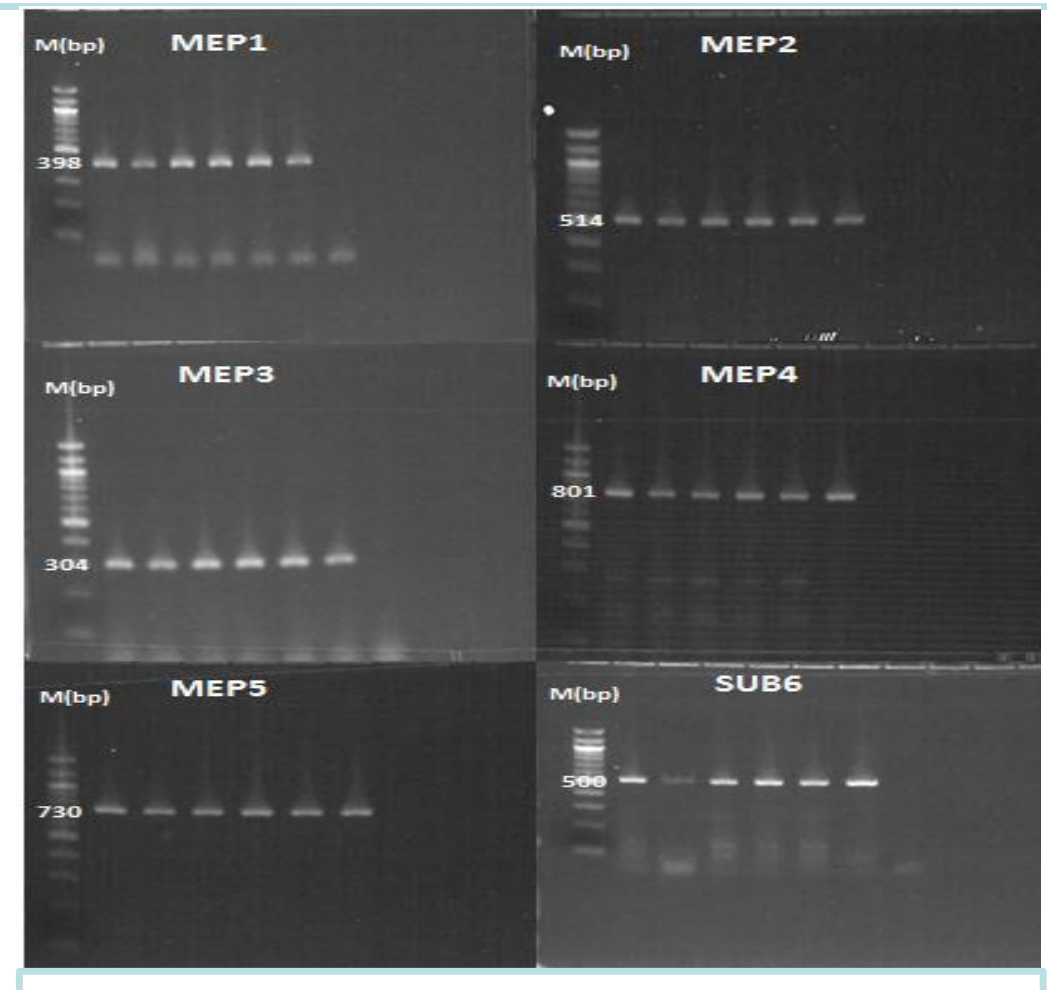

Figure 1 : Electrophoresis gels with Meps and Sub6

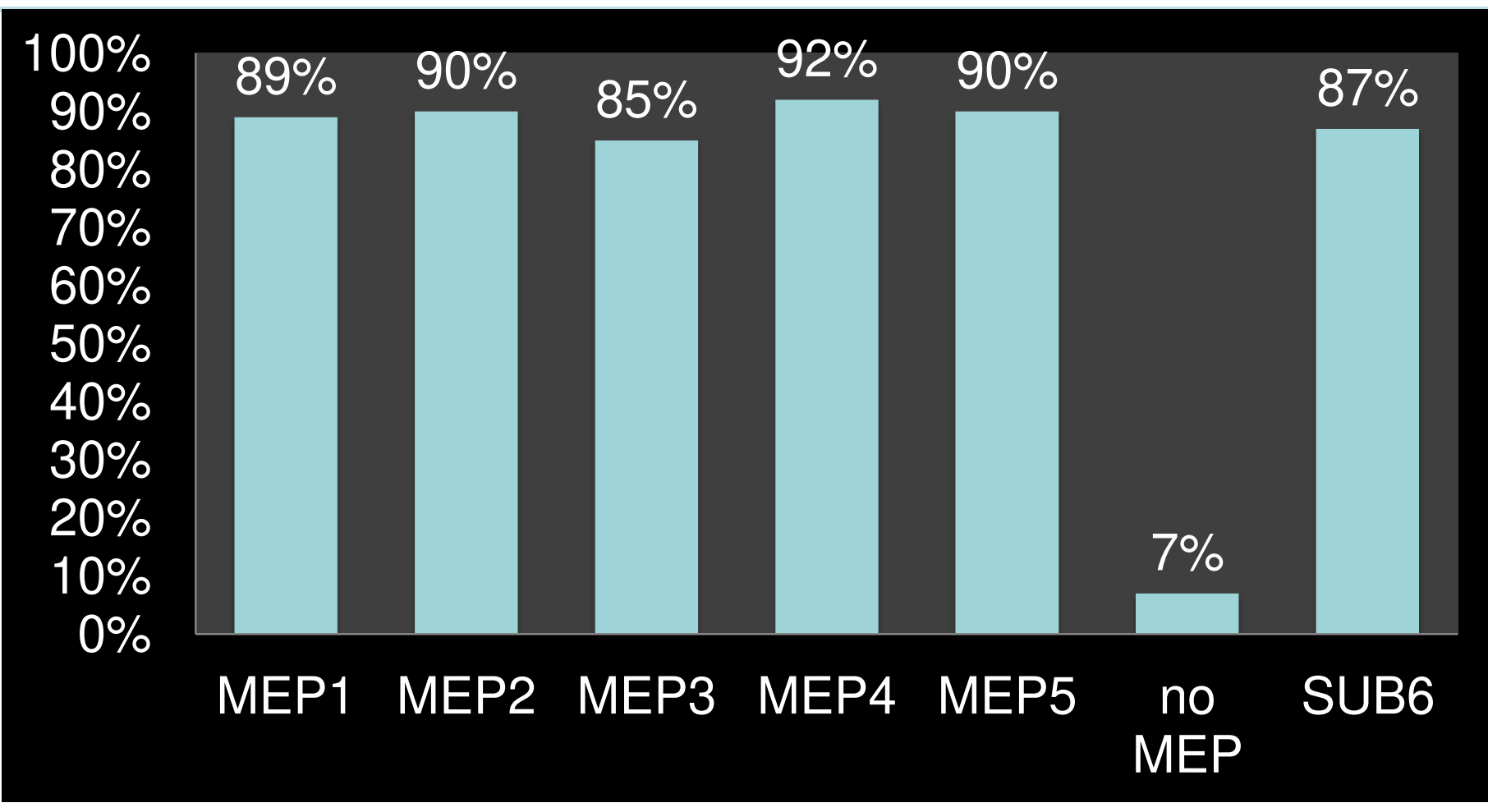

Figure 2 : Occurrence of Meps 1-5 \& Sub6 genes among the $103 \mathrm{M}$. audounii analysed strains 